\title{
Isothiocyanates repress estrogen receptor $\alpha$ expression in breast cancer cells
}

\author{
LIANGUO KANG ${ }^{1}$, LING DING ${ }^{2}$ and ZHAO-YI WANG ${ }^{1}$ \\ ${ }^{1}$ Department of Surgery, Creighton University Medical School, 2500 California Plaza, Omaha, \\ NE 68178, USA; ${ }^{2}$ Department of Oncology, Second Affiliated Hospital, Zhejiang University \\ Medical College, 88 JieFang Road, Hangzhou 310009, P.R. China
}

Received August 7, 2008; Accepted October 1, 2008

DOI: $10.3892 /$ or_00000206

\begin{abstract}
The isothiocyanates (ITCs) have long been known to possess chemopreventive activities for a variety of neoplasms including breast cancer, but the molecular mechanism by which ITCs prevent breast cancer development has not been established. In this study, we investigated the effects of benzyl and phenethyl isothiocyanate (BITC and PEITC) on the estrogen-stimulated growth of estrogen receptor $\alpha(\mathrm{ER} \alpha)$ positive breast cancer MCF7 and T-47D cells. BITC and PEITC inhibited estrogen-stimulated cell growth and reduced the expression levels of ER $\alpha$ in MCF7 and T-47D cells in a dose- and time-dependent and reversible manner. In addition, BITC and PEITC also abrogated the transcriptional activity of ER $\alpha$ and hence inhibited estrogen-stimulated expression of the estrogen responsive gene, $\mathrm{pS} 2$. These results demonstrated that BITC and PEITC function as potent ER $\alpha$ disruptors to abrogate mitogenic estrogen signaling in ER-positive breast cancer cells, which provides a molecular explanation for the growth inhibitory function of ITCs in breast cancer development, and a rational for further exploration of ITCs as chemopreventive agents for human mammary carcinogenesis.
\end{abstract}

\section{Introduction}

Breast cancer is a leading cause of cancer-related deaths among women in the United States. Despite the fact that significant advances have occurred in the understanding of the biology and etiology of breast cancer development, there is still no effective treatment and prevention for this deadly disease. Experimental evidence for the role of endogenous estrogens in breast cancer etiology has been well documented. It is believed that estrogen signaling is involved in mammary epithelial cell proliferation and differentiation. Dysregulated

Correspondence to: Dr Zhao-Yi Wang, Department of Surgery, Creighton University Medical School, Criss III, Room 352, 2500 California Plaza, Omaha, NE 68178, USA

E-mail: zywang@creighton.edu

Key words: isothiocyanate, breast cancer, estrogen receptor estrogen signaling increases the rate of cell proliferation and thus the risk of breast cancer.

The growth-promoting function of estrogen is mediated by specific receptors designated as estrogen receptors (ERs). ERs belong to the nuclear receptor superfamily and have two isoforms (ER $\alpha$ and ERß) encoded by independent genes (1). Both ERs are composed of three independent but interacting functional domains: the $\mathrm{A} / \mathrm{B}$ or $\mathrm{N}$-terminal domain, the $\mathrm{C}$ or DNA-binding domain, and the $\mathrm{D} / \mathrm{E} / \mathrm{F}$ or ligand-binding domain. In cell lines and some tissues, 17ß-estrodial (E2ß) elicits proliferation in the presence of $\mathrm{ER} \alpha$, but inhibits proliferation in the presence of ERß (1). Recently, loss of tumorigenesis was observed in ERß transfected ER-positive breast cancer MCF7 cells (2). Therefore, ER $\alpha$ is considered to be responsible for the estrogen-stimulated cell proliferation while ERß has protective activity. The binding of estrogen to $\mathrm{ER} \alpha$ leads to receptor phosphorylation, dimerization and recruitment of co-activators to the estrogen-bound receptor complex, which in turn binds the promoter regions of target genes via direct interaction with the DNA binding site known as estrogen response element (ERE) and activates transcription of target genes. Activated ER $\alpha$ can also transactivate additional target genes through protein-protein interaction with other transcription factors such as the Jun/Fos activator protein 1 (AP-1) and Sp1 $(3,4)$. Stimulation of target gene expression by $\mathrm{ER} \alpha$ in response to estrogen is prevailingly thought to be responsible for estrogen-stimulated cell proliferation. Thus, targeting ER $\alpha$ itself and ER $\alpha$-mediated mitogenic estrogen signaling provides an effective approach to treat or prevent ER-positive breast cancer.

Epidemiological and pharmacological evidence indicates that isothiocyanates (ITCs) have substantial chemopreventive activities against various types of cancer including breast, lung, bladder, pancreatic and prostate cancer (5-10). ITCs exist as conjugates in the genus Brassica of cruciferous vegetables (e.g., cabbage, cauliflower, brussels sprouts, watercress, broccoli, mustard) and the genus Raphanus (radishes and daikons) $(11,12)$. More than 25 natural and synthetic ITCs have been demonstrated to block chemicallyinduced carcinogenesis effectively by blocking carcinogen metabolic activation and enhancing carcinogen detoxification (13-16). In addition to their roles in cancer prevention, isothiocyanates also potently inhibit the malignant growth in 


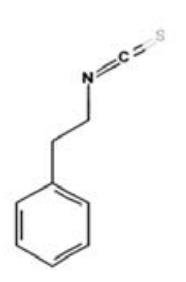

PEITC

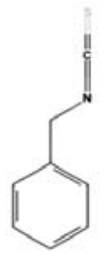

BITC

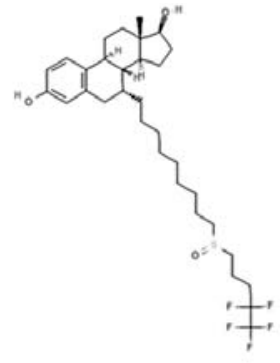

ICI 182,780
Figure 1. The chemical structures of phenethyl isothiocyanate (PEITC), benzyl isothiocyanate (BITC) and ICI 182,780.

cancer cells by inducing cell cycle arrest and apoptosis with little or no toxicity toward normal cells (17-19). Benzyl isothiocyanate (BITC) and phenethyl isothiocyanate (PEITC) (Fig. 1) are two well studied ITCs for their inhibitory functions in different cancer cells. BITC and PEITC were potent in inducing apoptosis and activating caspases in bladder cancer cells (20). It was also reported that BITC effectively suppressed growth of human breast cancer cells by causing G2-M phase cell cycle arrest and apoptosis induction (7). Hence, Tseng et al also examined the potency of BITC and PEITC as chemotherapy reagents for human breast cancer cells (21).

Recently, epidemiologic evidence indicated that dietary intake of dietary ITC-containing cruciferous vegetables may have preventive function against breast cancer development $(9,10)$. However, the molecular mechanisms by which dietary ITCs prevent human mammary carcinogenesis are not well established.

In the present study, we have demonstrated that two well studied ITCs, PEITC and BITC, significantly down-regulate $\mathrm{ER} \alpha$ expression, reduce $\mathrm{ER} \alpha$ transcriptional activity and inhibit growth of ER-positive breast cancer MCF7 and T-47D cells.

\section{Materials and methods}

Reagents. PEITC and BITC were purchased from SigmaAldrich (St. Louis, MO, USA). ICI 182,780 was purchased from Tocris (Ellisville, MO, USA). The Fugene/HD transfection reagent was purchased from Roche Diagnostics (Indianapolis, IN, USA). The Luciferase Assay System was purchased from Promega Corp. (Madison, WI, USA). The $\mathrm{ER} \alpha$ polyclonal antibody was obtained from Lab Vision Corp. (Fremont, CA, USA). The ER $\alpha$ antibody, the actin antibody, the goat anti-rabbit IgG-HRP and the donkey anti-goat IgGHRP were purchased from Santa Cruz Biotechnology (Santa Cruz, CA, USA). MG-132 was purchased from CalBiochem (San Diego, CA, USA). The ECL Western Blotting Detection Reagents were purchased from GEHealthcare (Little Chalfont, Buckinghamshire, UK). The 'Concert' cytoplasmic RNA purification reagent was from Invitrogen (Carlsbad, CA, USA), and the ProtoScript II RT-PCR kit was purchased from New England BioLabs (Ipswich, MA, USA).

Cell culture. ER-positive breast cancer cell line, MCF7 and T-47D from ATCC (Manassas, VA, USA) were maintained in Improved Minimal Essential Medium (IMEM) from
Invitrogen supplemented with $10 \%$ heat-inactivated fetal bovine serum (FBS), $1 \%$ non-essential amino-acids, $1 \%$ HEPES buffer, $1 \%$ antibiotic-antimycotic from Invitrogen, and $2 \mu \mathrm{g} / \mathrm{ml}$ bovine insulin (Sigma, St. Louis, MO, USA) at $37^{\circ} \mathrm{C}$ under $5 \% \mathrm{CO}_{2}$ in a humidified incubator.

Cell growth inhibition assays. MCF7 and T-47D cells were changed to medium containing 5\% charcoal-dextran stripped FBS for two days, and then seeded in $\Phi 35-\mathrm{mm}$ dishes at a density of $5 \times 10^{4}$ cells/dish in IMEM supplemented with $2.5 \%$ charcoal-dextran stripped FBS. After $24 \mathrm{~h}$, cells were treated with vehicle (DMSO) and different concentrations of PEITC, BITC or ICI 182,780 for 3 days. Cells were then trypsinized and counted with a hemocytometer. Three dishes were used for each concentration point and the experiments were repeated three times.

To test the effects of the ITCs on estrogen-stimulated growth, MCF7 and T-47D cells were changed to medium containing 5\% charcoal-dextran stripped FBS for two days, and then seeded in $\Phi 35-\mathrm{mm}$ dishes at a density of $5 \times 10^{4}$ cells/ dish in IMEM containing $2.5 \%$ charcoal-dextran stripped FBS for another $24 \mathrm{~h}$. Cells were treated with $1 \mathrm{nM}$ of $173-$ estradiol (E2) alone or together with different concentrations of PEITC, BITC or ICI 182,780 for 3 days. The cells were then trypsinized and counted with a hemocytometer.

Western blot analysis. Cells were washed with PBS twice and lysed with RIPA buffer with $1 \%$ proteinase inhibitor cocktail solution and $1 \%$ phosphatase inhibitor cocktail solution (Sigma). The cell lysates were boiled for $5 \mathrm{~min}$ in SDS gelloading buffer and separated on a 10\% SDS-PAGE gel. After electrophoresis, the proteins were transferred to a PVDF membrane (Bio-Rad Laboratories, Hercules, CA, USA). The membranes were probed with appropriate primary antibodies and visualized with corresponding secondary antibodies and the ECL Western Blotting Detection Reagents. The same membranes were stripped and reprobed with an antibody against $\beta$-actin as loading controls.

DNA transfection and luciferase assay. MCF7 and T-47D cells maintained in IMEM medium containing 10\% FBS were changed to medium containing $5 \%$ charcoal-dextran stripped FBS for two days, and then were seeded in $\$ 35-\mathrm{mm}$ dishes at a density of $2 \times 10^{5}$ cells/dish for another day. Cells were transfected with the p2xERE-Luc reporter plasmid (a kind gift from Dr Katarine Pettersson at Karolinska Institute, Sweden) and a $\beta$-galactosidase expression plasmid, pCMV- $\beta$ (Clontech Laboratories, Inc., Palo Alto, CA), to establish transfection efficiency. Twelve hours after transfection, cells were treated with $1 \mathrm{nM}$ of E2 alone or together with different concentrations of PEITC, BITC or ICI 182,780. Twenty-four hours after transfection, cell extracts were prepared and aliquots were normalized for transfection efficiency by assay of $B$-galactosidase activity. Luciferase assays were performed using the luciferase reporter system in a TD 20/20 luminometer as instructed by the manufacturer.

$R N A$ purification and $R T-P C R$. To examine the downregulation of ER $\alpha$ mRNA by ITCs, MCF7 and T-47D cells cultured in IMEM containing $2.5 \%$ charcoal-dextran stripped 
A

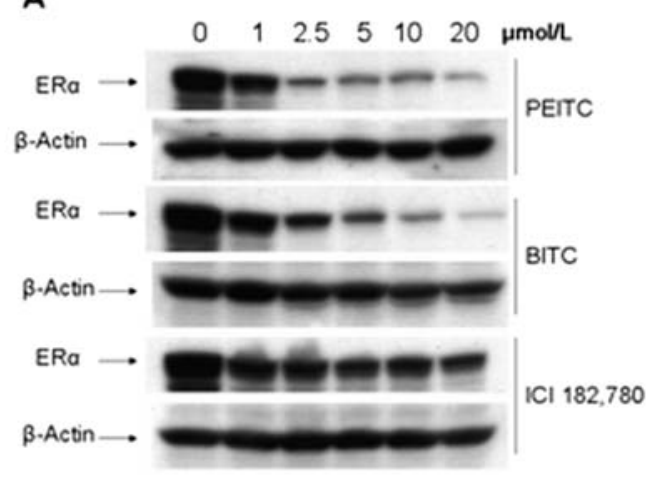

C

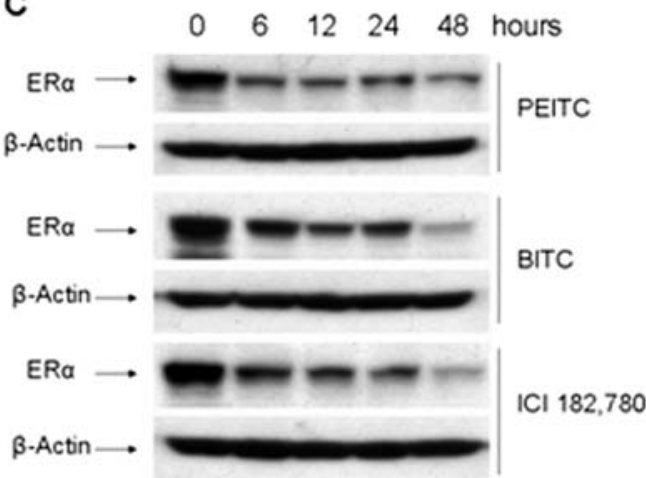

E

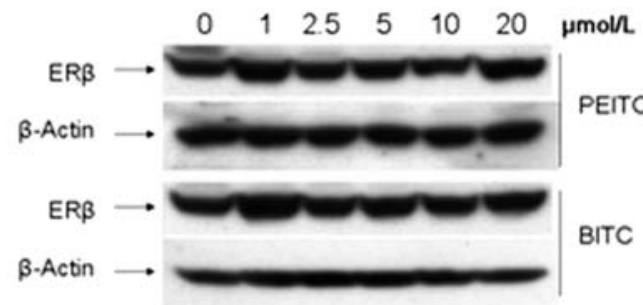

B

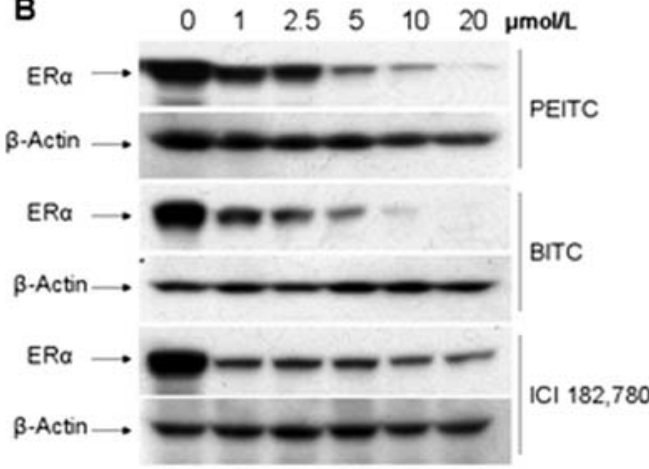

D

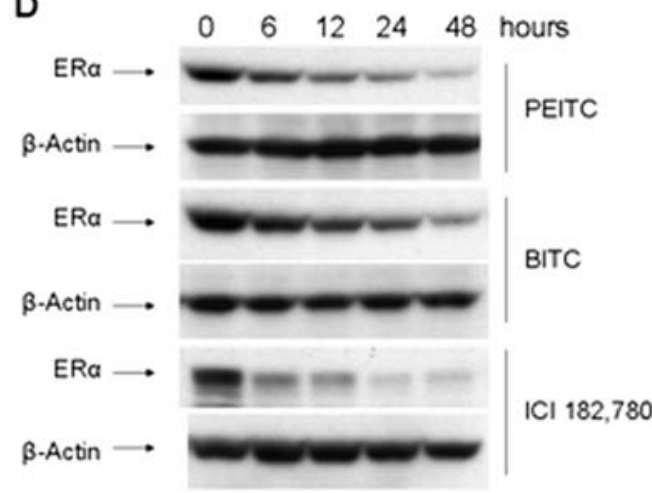

$\mathbf{F}$

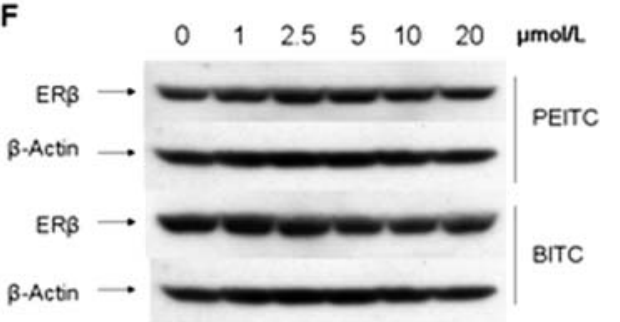

Figure 2. PEITC and BITC reduce the expression level of ER $\alpha$ protein as demonstrated by Western blot analysis. MCF7 (A) and T-47D (B) cells were treated with vehicle (DMSO, 0), 1, 2.5, 5, 10 and $20 \mu \mathrm{M}$ of PEITC, BITC or ICI 182,780 for $12 \mathrm{~h}$ and lysed for Western blot analysis with anti-ER $\alpha$ and anti- $\beta$-actin antibodies. MCF7 (C) and T-47D (D) cells were treated with $10 \mu \mathrm{M}$ of PEITC, BITC or ICI 182,780 for indicated time-points, and lysed for Western blot analysis with anti-ER $\alpha$ and anti-ß-actin antibodies. MCF7 (E) and T-47D (F) cells were treated with vehicle (DMSO, 0), 1, 2.5, 5, 10 and $20 \mu \mathrm{M}$ of PEITC or BITC for $12 \mathrm{~h}$, and lysed for Western blot analysis with anti-ERß and anti-ß-actin antibodies.

FBS were treated with different concentrations of PEITC, BITC or ICI 182,780 for $12 \mathrm{~h}$. To assess the effects of ITCs on estrogen-stimulated gene expression, MCF7 and T-47D cells maintained in medium containing $2.5 \%$ charcoal-dextran stripped FBS were treated with $1 \mathrm{nM}$ of E2B alone or together with different concentrations of PEITC, BITC or ICI 182,780 for $12 \mathrm{~h}$. Total RNA was prepared with the 'Concert' cytoplasmic RNA purification reagent. One microgram of total RNA was reverse transcribed using ProtoScript II RT-PCR kit with random primers. The reverse transcription reaction was performed at $42^{\circ} \mathrm{C}$ for $1 \mathrm{~h}$. Semi-quantitative RT-PCR of $\mathrm{ER} \alpha, \beta$-actin and $\mathrm{pS} 2$ were done using gene specific primers synthesized by Integrated DNA Technologies, Inc. (Coralville, IA, USA). The following are the primer sequences for ER $\alpha$, B-actin and $\mathrm{pS} 2$.

ER $\alpha$ : forward primer, 5'-CAC TCA ACA GCG TGT CTC CGA-3'; reverse primer, 5'-CCA ATC TTT CTC TGC CAC CCT G-3'. ß-actin: forward primer, 5'-TGA CGG GGT CAC CCA CAC TGT GCC CAT CTA-3'; reverse primer,
5'-CTA GAA GCA TTT GCG GTG GAC GAT GGA GGG-3'. pS2: forward primer, 5'-TGG AGA ACA AGG TGA TCT GC-3'; reverse primer, 5'-ATC TGT GTT GTG AGC CGA GG-3'.

The procedure of PCR for ER $\alpha$ and $\beta$-actin was carried out as following: first a denaturing at $95^{\circ} \mathrm{C}$ for $1 \mathrm{~min}$, then the remaining PCR was performed at $94^{\circ} \mathrm{C}$ for $30 \mathrm{sec}, 58^{\circ} \mathrm{C}$ for $30 \mathrm{sec}$ and $68^{\circ} \mathrm{C}$ for $1 \mathrm{~min}$ ( 35 cycles for $\mathrm{ER} \alpha$ and 25 cycles for $\beta$-actin). PCR for $\mathrm{pS} 2$ was started with a denaturing at $94^{\circ} \mathrm{C}$ for $3 \mathrm{~min}$, then $94^{\circ} \mathrm{C}$ for $45 \mathrm{sec}, 55^{\circ} \mathrm{C}$ for $45 \mathrm{sec}$ and $72^{\circ} \mathrm{C}$ for $45 \mathrm{sec}$ ( 30 cycles). At the end, there was a final elongation at $72^{\circ} \mathrm{C}$ for $7 \mathrm{~min}$. PCR products were analyzed by electrophoresis on a $1.5 \%$ agarose gel and visualized by ethidium bromide staining under UV illumination.

Statistical analysis. Data were summarized as the mean \pm standard error (SE) using GraphPad InStat software program. Tukey-Kramer Multiple Comparisons Test was used, and the significance was accepted for P-values of $<0.05$. 


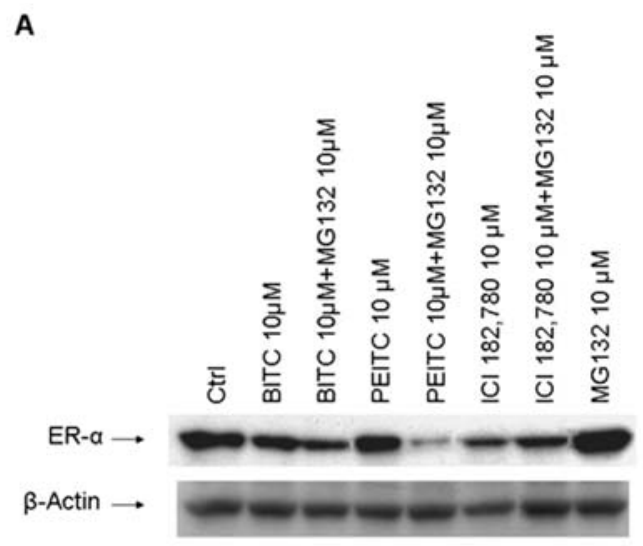

B

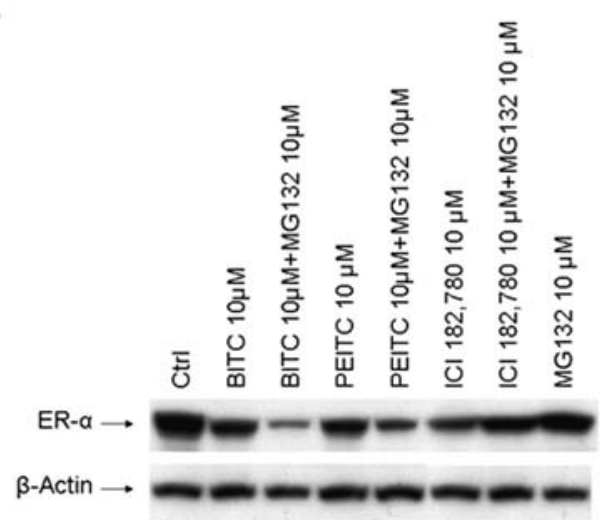

Figure 3. Effects of proteasome inhibitors on ER $\alpha$ down-regulation induced by PEITC, BITC or ICI 182,780 in MCF7 and T-47D cells. (A) MCF7 cells were incubated for $12 \mathrm{~h}$ in the vehicle (DMSO, Ctrl), $10 \mu \mathrm{M}$ PEITC, BITC or ICI 18,780 with or without MG $13210 \mu \mathrm{M}$ and lysed for Western blot analysis with anti-ER $\alpha$ and anti- $\beta$-actin antibodies. (B) T-47D cells were incubated for $12 \mathrm{~h}$ in the vehicle (DMSO, Ctrl), $10 \mu \mathrm{M}$ PEITC, BITC or ICI 18,780 with or without MG $13210 \mu \mathrm{M}$ and lysed for Western blot analysis with anti-ER $\alpha$ and anti- $\beta$-actin antibodies.

\section{Results}

PEITC and BITC repress ERa expression in MCF7 and T-47D cells. MCF7 and T-47D cells express high levels of ER $\alpha$ and strongly response to mitogenic estrogen stimulation. Previously, it was reported that BITC and PEITC are potent growth inhibitors in breast cancer MCF7 cells (21), and PEITC repressed the expression of androgen receptor and inhibited growth of prostate cancer cells (22). Hence, we decided to examine the ER $\alpha$ expression in PEITC- or BITC-treated MCF7 and T-47D cells. Cells were incubated with different concentrations of PEITC or BITC for $12 \mathrm{~h}$. Western blot analysis was performed to assess ER $\alpha$ expression. We found that the expression levels of ER $\alpha$ were dramatically reduced in PEITC- or BITC-treated MCF7 and T-47D cells in a dosedependent manner (Fig. 2A and B). The well-known estrogen receptor disruptor, ICI 182,780 (Fig. 1) was also able to reduce levels of ER $\alpha$ expression but with much less efficiency compared to both BITC and PEITC at $12 \mathrm{~h}$ under higher concentrations (Fig. 2A and B). Furthermore, the expression levels of ER $\alpha$ in MCF7 and T-47D cells treated with $10 \mu \mathrm{M}$ of PEITC or BITC for different time-points were also examined (Fig. 2C and D). ER $\alpha$ expression levels were started to reduce after treatment of PEITC and BITC for $6 \mathrm{~h}$, and continued to decrease to a very low level at $48 \mathrm{~h}$ (Fig. 2C and D). As a positive control, ICI 182,780 treatment for $48 \mathrm{~h}$, exhibited a strong reduction of ER $\alpha$ expression to a level comparable to the levels in cells treated with PEITC or BITC (Fig. 2C and D). However, both PEITC and BITC had no effect on ERß expression (Fig. 2E and F).

PEITC and BITC repress ER expression at the transcription level. It is well established that ICI 182,780 triggers the degradation of ER $\alpha$ protein through proteasome-dependent proteolysis (23). We decided to test whether the downregulation of ER $\alpha$ protein by BITC and PEITC was via the same mechanism. MCF7 and T-47D cells were treated with $10 \mu \mathrm{M}$ of BITC or PEITC alone or together with proteasome inhibitor MG-132 $10 \mu \mathrm{M}$ respectively for $12 \mathrm{~h}$. Western blot analysis revealed that proteasome inhibitor MG-132 was unable to reverse the expression levels of ER $\alpha$ protein downregulated by PEITC and BITC (Fig. 3). On the contrary, a further reduction of $\mathrm{ER} \alpha$ protein expression was observed in the cells treated with ITCs and MG-132 (Fig. 3). However, the proteasome inhibitor MG132 efficiently blocked ICI 182,780 induced down-regulation of ER $\alpha$ protein (Fig. 3), consistent with the previous reports that ICI 182,780 induces degradation of ER $\alpha$ protein through the proteasome system $(23,24)$. Our results thus suggested that PEITC and BITC functions through a different mechanism to repress ER $\alpha$ expression.

We then examined the mRNA levels of ER $\alpha$ in MCF7 and T-47D cells treated with different concentrations of PEITC or BITC for $12 \mathrm{~h}$ by RT-PCR analysis. We found that mRNA levels of ER $\alpha$ were dramatically reduced after the treatment of PEITC or BITC starting at $5 \mu \mathrm{M}$ (Fig. 4), indicating that the suppression of ER $\alpha$ expression by PEITC and BITC occurs at the transcription level. While in ICI 182,780 treated cells, no change of ER $\alpha$ mRNA level was observed (Fig. 4), consistent with the previous report that ICI 182,780 has no effect on ER $\alpha$ transcription (23).

Down-regulation of ERa expression by PEITC and BITC is reversible. To further determine if the down-regulation of $\mathrm{ER} \alpha$ by PEITC and BITC is a reversible process, the MCF7 and T-47D cells were treated with $10 \mu \mathrm{M}$ of PEITC or BITC for $12 \mathrm{~h}$, then washed with PBS twice and changed to normal medium without PEITC and BITC. The cells were harvested at different time-points after PEITC and BITC withdrawal and examined for ER $\alpha$ expression with Western blot analysis. The levels of ER $\alpha$ expression were almost fully recovered after $24 \mathrm{~h}$ (Fig. 5), indicating the suppression activities of PEITC and BITC is reversible. However, ER $\alpha$ down-regulation mediated by ICI 182,780 was not fully recovered by $24 \mathrm{~h}$ (Fig. 5).

PEITC and BITC inhibit ERa transcriptional activity. To further determine if PEITC and BITC would inhibit transcriptional signaling mediated by ER $\alpha$. Transient transfection assays were conducted in MCF7 and T-47D cells using a luciferase reporter plasmid containing two copies of ERE binding sites. We found that E2ß induced the luciferase 
A
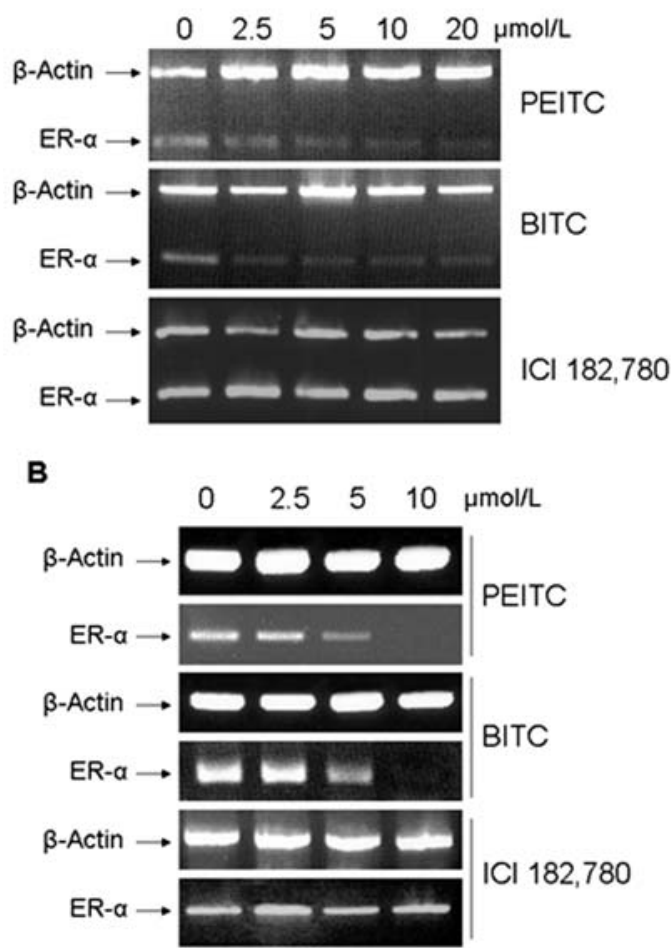

Figure 4. Effects of PEITC, BITC or ICI 182,780 on the mRNA levels of ER $\alpha$. MCF7 (A) and T-47D (B) cells were incubated for $12 \mathrm{~h}$ in vehicle (DMSO, 0), 2.5, 5, 10 and $20 \mu \mathrm{M}$ of PEITC, BITC or ICI 182,780. Total RNA were extracted and $1 \mu \mathrm{g}$ of total RNA were used for semi-quantitative RT-PCR using specific primers for ER $\alpha$ and $\beta$-actin as described in methods. RT-PCR products were separated by $1.5 \%$ agarose gels and stained with ethidium bromide.

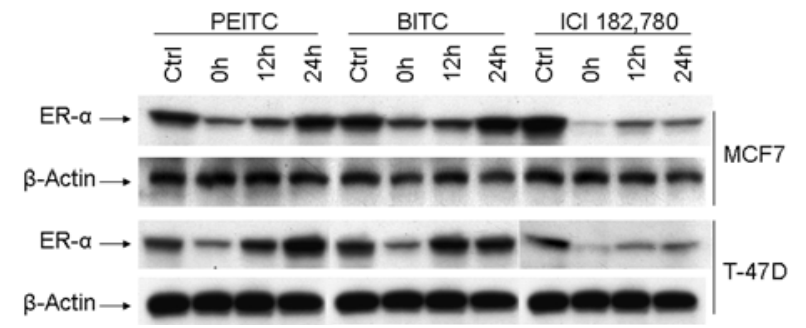

Figure 5. PEITC and BITC inhibitory effects on ER $\alpha$ expression are reversible. MCF7 and T-47D cells were incubated for $12 \mathrm{~h}$ in the absence (Ctrl) or presence of $10 \mu \mathrm{M}$ PEITC, BITC or ICI 182,780. Then the medium were removed, washed cells with PBS twice, and replaced with fresh medium. Cells were then harvested after different time intervals, Western blot analysis were then performed with anti-ER $\alpha$ and anti- $\beta$-actin antibodies.

reporter activity about 3-fold, which was then attenuated by PEITC or BITC in a dose-dependent manner (Fig. 6). As a positive control, the pure antagonist ICI 182,780 repressed the luciferase activity induced by estrogen treatment (Fig. 6).

We then examined the effects of PEITC and BITC on the estrogen-induced expression of $\mathrm{pS} 2$, an $\mathrm{ER} \alpha$ targeting gene, in MCF7 and T-47D cells using RT-PCR analysis. We found that $\mathrm{E} 2 \mathrm{~B}$ at $1 \mathrm{nM}$ induced $\mathrm{pS} 2$ expression in MCF7 and T-47D cells, which was strongly inhibited by both PEITC and BITC (Fig. 7). ICI 182,780 also antagonized the stimulatory effect of E2 in MCF7 and T-47D cells (Fig. 7). These results strongly indicated that PEITC and BITC are able to function as potent estrogen antagonists as the pure antiestrogen ICI 182,780.

\section{Discussion}

A number of studies have shown that $\mathrm{ER} \alpha$ expression is elevated from very early stages of mammary carcinogenesis and thus is a risk factor for progression to invasive breast cancer (25-27). The ER $\alpha$ expression level in ER-positive tumors is greatly increased as compared to the neighboring normal tissues (28). This strong correlation between ER $\alpha$ expression and breast cancer development had made ER $\alpha$ an important target for drug development.

Antiestrogens designed to target ER $\alpha$ can be classified into two major groups: analogs of tamoxifen and its metabolites such as 4-hydroxytamoxifen that have mixed estrogenic/ antiestrogenic actions, and pure antiestrogens such as ICI 182,780 . Tamoxifen is commonly used for adjuvant therapy of breast cancer and is a key drug for breast cancer chemoprevention in high-risk women. ICI 182,780 impairs ER $\alpha$ dimerization and inhibits nuclear localization of ER $(29,30)$. In addition, ICI 182,780 also accelerates degradation of the $\mathrm{ER} \alpha$ protein without a reduction of ER $\alpha$ mRNA level (24). Thus, ICI 182,780 functions as an estrogen receptor disruptor to enhance degradation of ER $\alpha$ protein, resulting in an inhibition of mitogenic estrogen signaling.

In this report, we have demonstrated that PEITC and BITC, two well studied ITCs, strongly suppress ER $\alpha$ expression. The exposure of ER-positive breast cancer MCF7 and T-47D cells to PEITC or BITC resulted in a reduced level of ER $\alpha$ expression as demonstrated by Western blot analysis. The ER $\alpha$ expression was down-regulated by PEITC or BITC at a level comparable to the levels in cells treated with the pure estrogen antagonist ICI 182,780. We also found that proteasome inhibitor MG132 failed to reverse the downregulation of ER $\alpha$ expression mediated by PEITC and BITC while efficiently restored the levels of ER $\alpha$ protein expression down-regulated by ICI 182,780 . Thus, our results demonstrated that PEITC and BITC down-regulate ER $\alpha$ expression through a mechanism other than enhanced protein degradation through the proteasome system. A similar phenomenon was reported in the down-regulation of androgen receptor (AR) expression mediated by PEITC in prostate cancer cells; MG132 could not reverse the AR down-regulation after a 24-h incubation with PEITC (22). This result together with ours suggested that PEITC and BITC may function at the transcriptional level to negatively regulate gene expression.

We then used semi-quantitative RT-PCR analysis to demonstrate that PEITC and BITC could reduce the ER $\alpha$ transcripts in ER-positive breast cancer cells while ICI 182,780 had no effect on ER $\alpha$ mRNA as reported before $(23,24)$. Thus, PEITC and BITC function as a negative regulator of $\mathrm{ER} \alpha$ transcription. However, the molecular mechanism by which PEITC and BITC inhibit ER $\alpha$ transcription was not clear right now. Recently, it was reported that PEITC repress AR expression in prostate cancer cells at the transcriptional level through inhibition of the transcription 

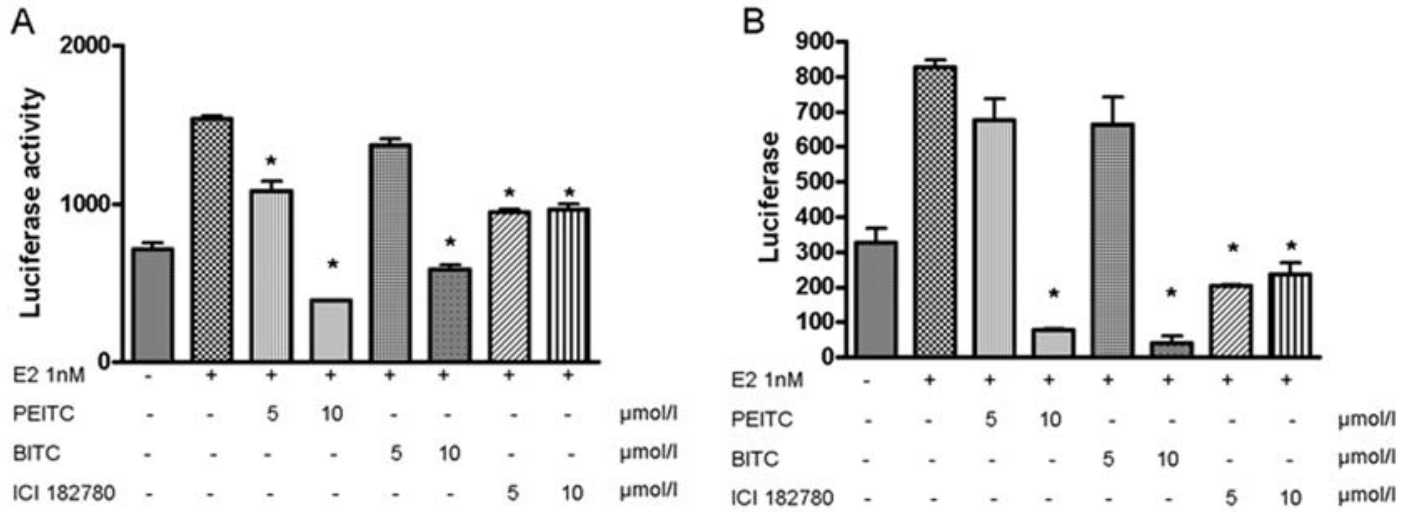

Figure 6. PEITC and BITC inhibit ER $\alpha$ transcriptional activity. MCF7 (A) and T-47D (B) cells maintained in IMEM containing 2.5\% charcoal-stripped FBS were transfected with the 2xERE-TK-Luc plasmid and treated with vehicle (DMSO), $1 \mathrm{nM}$ of $17 \beta$-estradiol (E2 $1 \mathrm{nM}$ ) or together with 5 and $10 \mu \mathrm{M}$ of PEITC, BITC or ICI 182,780, respectively for $12 \mathrm{~h}$. Cells were harvested for luciferase assay. The data were based on the mean of 3 independent experiments with the mean \pm SE shown. ${ }^{*} \mathrm{P}<0.001$ (compare to the $\mathrm{E} 21 \mathrm{nM}$ group).

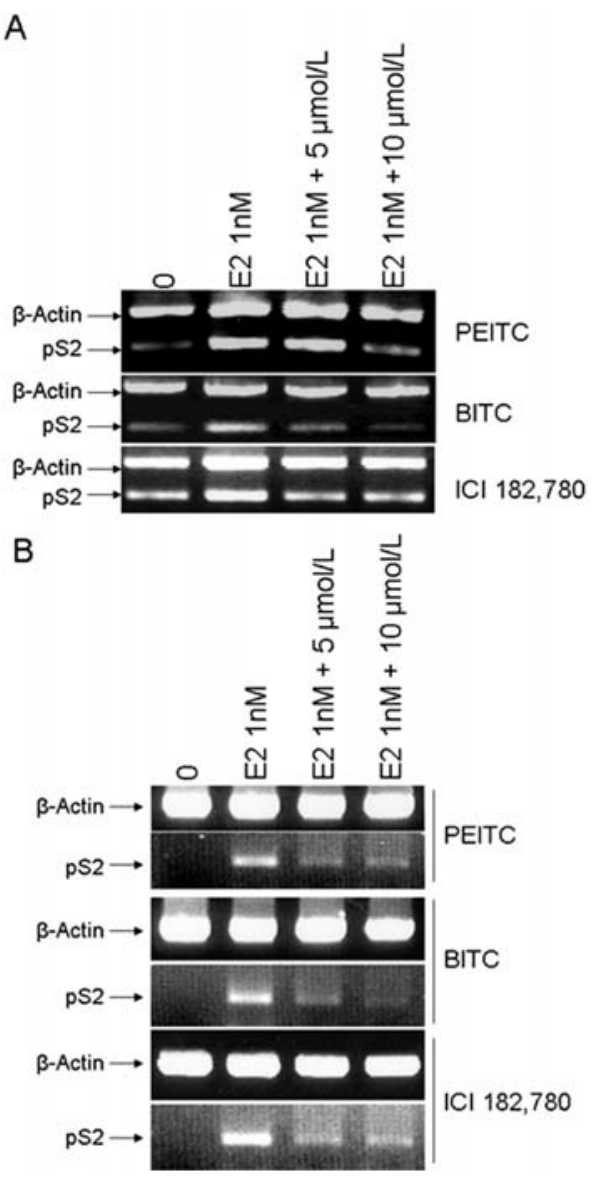

Figure 7. Effects of PEITC, BITC or ICI 182,780 on ER $\alpha$ targeting gene pS2. MCF7 (A) and T-47D (B) cells maintained in IMEM with $2.5 \%$ charcoal-stripped FBS were treated with vehicle (DMSO), $1 \mathrm{nM}$ of $173-$ estradiol (E2 $1 \mathrm{nM}$ ) alone or together with 5 and $10 \mu \mathrm{M}$ of PEITC, BITC or ICI 182,780 for $12 \mathrm{~h}$. Total RNA was extracted and $1 \mu \mathrm{g}$ of total RNA was used for semi-quantitative RT-PCR using specific primers for $\mathrm{pS} 2$ and $\beta$-actin. RT-PCR products were separated in $1.5 \%$ agarose gels and stained with ethidium bromide.

factor Sp1 expression (22). There are several Sp1 binding sites in the proximal promoter region of ER $\alpha$ that are essential for maximum ER $\alpha$ transcription (31). It is thus possible that PEITC or BITC also inhibits Sp1 expression in ER-positive breast cancer MCF7 and T-47D cells, which then in turn attenuates ER $\alpha$ transcription. In addition, it was reported that $\mathrm{ER} \alpha$ can activate transcription via formation of an ER-Sp1 complex on the GC-rich Sp1 binding sites in the promoter region of target genes and ER $\alpha$ enhances Sp1 DNA binding in a hormone-independent manner (32). In ER $\alpha$ promoter region, the formation of a multi-protein complex composed of $\mathrm{Sp} 1, \mathrm{ER} \alpha$ and upstream stimulating factor 1 (USF-1) is essential for optimum ER $\alpha$ transcription (31). ER $\alpha$ might autoregulate the expression of itself through interaction with $\mathrm{Sp} 1$ bound to its promoter. Down-regulation of both ER $\alpha$ and Sp1 by PEITC and BITC may abrogate this positive feedback of $\mathrm{ER} \alpha$ transcription regulation and further down-regulate $\mathrm{ER} \alpha$ promoter activity.

As a result of ER $\alpha$ down-regulation, the transcriptional activities of ER $\alpha$ were reduced in ER-positive breast cancer MCF7 and T-47D cells treated with PEITC or BITC. Estrogen stimulated promoter activity of the ERE containing reporter plasmid and expression of the endogenous ER $\alpha$ targeting gene $\mathrm{pS} 2$ were dramatically reduced in the presence of PEITC or BITC. These results further confirm that PEITC and BITC repress ER $\alpha$ expression and its transcriptional activities. These data also indicate that PEITC and BITC may function as an inhibitor of the mitogenic estrogen signaling.

In humans, the maximal plasma concentration of PEITC after ingestion of $100 \mathrm{~g}$ watercress can reach as high as $1155 \mathrm{nM}$ (ranges between 673 and $1155 \mathrm{nM}$, mean $928.5 \pm 250.7 \mathrm{nM}$ ) within $1.5 \mathrm{~h}$ (ranges between 1.5 and $4 \mathrm{~h}$, mean $2.6 \pm 1.1 \mathrm{~h})(33)$, and $1.04 \pm 0.22 \mu \mathrm{M}$ concentration can be reached after a single 40-mg dose of PEITC (34). In animal experiments, the maximal plasma concentration of PEITC can reach $9.2 \pm 0.6$ or $42.1 \pm 11.4 \mu \mathrm{M}$ after doses of 10 and $100 \mu \mathrm{mol} / \mathrm{kg}$ in rats (35). Therefore, the PEITC and BITC concentrations required to produce statistically significant inhibition of ER $\alpha$ expression in human breast cancer cells may be achievable in vivo.

It was reported that BITC induces the G2-M phase cell cycle arrest and cell apoptosis in ER-negative breast cancer MDA-MB-231 cells and ER-positive breast cancer MCF7 cells (7). The cell cycle arrest was associated with a decrease in expression levels of proteins involved in regulation of G2-M 
transition, including cyclin B1, cyclin-dependent kinase 1 and cell division cycle 25C (7). The apoptosis correlated with induction of proapoptotic proteins Bax and Bak, and downregulation of anti-apoptotic proteins $\mathrm{Bcl}-2$ and $\mathrm{Bcl}-\mathrm{x}_{\mathrm{L}}$ (7). It was also reported that ITC treatment causes mitochondrial damage and caspase-9 activation (8). PEITC could also downregulate JNK-specific phosphatase and function to activate JNK through suppression of JNK dephosphorylation (36). Thus, ITCs such as PEITC and BITC may regulate many cellular processes that acts together to result in growth inhibition and apoptosis induction. However, the cytotoxic effects of PEITC and BITC could not account for the downregulated levels of ER $\alpha$ expression observed, since the doses of PEITC and BITC that effectively suppress ER $\alpha$ expression did not promote significant cell death in $12 \mathrm{~h}$. Moreover, because ER $\alpha$ expression was totally restored after the withdrawal of PEITC and BITC for $24 \mathrm{~h}$, the possibility that the apoptotic cell death induced by PEITC and BITC contributed to the down-regulation of $\mathrm{ER} \alpha$ expression could be excluded.

Our findings, that the reversible down-regulation of ER $\alpha$ expression and mitogenic estrogen signaling by PEITC and BITC revealed that another important signaling pathway that is influenced by ITCs. Our experimental results thus strongly support the idea that the ITCs from cruciferous vegetables are important dietary factors for breast cancer chemoprevention.

\section{Acknowledgements}

This study was supported by NIH grant DK070016 (Z.Y. Wang), the Susan G. Komen Breast Cancer Foundation BCTR81906 (Z.Y. Wang) and Nebraska Tobacco Settlement Biomedical Research Program Award (LB-595) to Z.Y. Wang.

\section{References}

1. Imamov O, Shim GJ, Warner M and Gustafsson JA: Estrogen receptor beta in health and disease. Biol Reprod 73: 866-871, 2005.

2. Behrens D, Gill JH and Fichtner I: Loss of tumorigenicity of stably ERß-transfected MCF7 breast cancer cells. Mol Cell Endocrinol 274: 19-29, 2007.

3. Kushner PJ, Agard DA, Greene GL, Scanlan TS, Shiau AK, Uht RM and Webb P: Estrogen receptor pathways to AP-1. J Steroid Biochem Mol Biol 74: 311-317, 2000.

4. Saville B, Wormke M, Wang F, Nguyen T, Enmark E, Kuiper G, Gustafsson JA and Safe S: Ligand-, cell- and estrogen receptor subtype $(\alpha / \beta)$-dependent activation at GC-rich (Sp1) promoter elements. J Biol Chem 275: 5379-5387, 2000.

5. Block G, Patterson B and Subar A: Fruit, vegetables and cancer prevention: a review of the epidemiological evidence. Nutr Cancer 18: 1-29, 1992.

6. Verhoeven DT, Goldbohm RA, van Poppel G, Verhagen H and van den Brandt PA: Epidemiological studies on brassica vegetables and cancer risk. Cancer Epidemiol Biomarkers Prev 5: 733-748, 1996.

7. Xiao D, Vogel V and Singh SV: Benzyl isothiocyanate-induced apoptosis in human breast cancer cells is initiated by reactive oxygen species and regulated by Bax and Bak. Mol Cancer Ther 5: 2931-2945, 2006

8. Tang L and Zhang Y: Mitochondria are the primary target in isothiocyanate-induced apoptosis in human bladder cancer cells. Mol Cancer Ther 4: 1250-1259, 2005.

9. Fowke JH, Chung FL, Jin F, Qi D, Cai Q, Conaway C, Cheng JR, Shu XO, Gao YT and Zheng W: Urinary isothiocyanate levels, Brassica, and human breast cancer. Cancer Res 63: 3980-3986, 2003.
10. Ambrosone CB, McCann SE, Freudenheim JL, Marshall JR, Zhang Y and Shields PG: Breast Cancer risk in premenopausal women is inversely associated with consumption of broccoli, a source of isothiocyanates, but is not modified by GST genotype J Nutr 134: 1134-1138, 2004.

11. Fenwick GR, Heaney RK and Mullin WJ: Glucosinolates and their breakdown products in food and food plants. Crit Rev Food Sci Nutr 18: 123-201, 1983

12. Getahun SM and Chung FL: Conversion of glucosinolates to isothiocyanates in humans after ingestion of cooked watercress. Cancer Epidemiol Biomarks Prev 8: 447-451, 1999.

13. Talalay P and Fahey JW: Phytochemicals from cruciferous plants protect against cancer by modulating carcinogen metabolism. J Nutr 131: S3027-S3033, 2001.

14. Zhang Y, Talalay P, Cho CG and Posner GH: A major inducer of anticarcinogenic protective enzymes from broccoli: isolation and elucidation of structure. Proc Natl Acad Sci USA 89: 2399-2403, 1992

15. Mahéo K, Morel F, Langouët S, Kramer H, Le Ferrec E, Ketterer B and Guillouzo A: Inhibition of cytochrome P-450 and induction of glutathione S-transferases by sulforaphane in primary human and rat hepatocytes. Cancer Res 57: 3649-3652, 1997.

16. Dick RA and Kensler TW: Chemoprotective potential of phase 2 enzyme inducers. Expert Rev Anticancer Ther 2: 581-592, 2002.

17. Xiao D, Srivastava SK, Lew KL, Zeng Y, Hershberger P, Johnson CS, Trump DL and Singh SV: Allyl isothiocyanate, a constituent of cruciferous vegetables inhibits proliferation of human prostate cancer cells by causing $\mathrm{G} 2 / \mathrm{M}$ arrest and inducing apoptosis. Carcinogenesis 24: 891-897, 2003.

18. Hu R, Kim BR, Chen C, Hebbar C and Kong AN: The role of JNK and apoptotic signaling pathways in PEITC-mediated responses in human HT-29 colon adenocarcinoma cell. Carcinogenesis 24: 1361-1367, 2003.

19. Srivastava SK and Singh SV: Cell cycle arrest and apoptosisinduced by benzyl isothiocyanate are associated with inhibition of nuclear factor kappa B activation in human pancreatic cancer cells. Carcinogenesis 25: 1701-1709, 2004.

20. Tang L and Zhang Y: Dietary isothiocyanates inhibit the growth of human bladder carcinoma cells. J Nutr 134: 2004-2010, 2004.

21. Tseng E, Scott-Ramsay EA and Morris ME: Dietary organic isothiocyanates are cytotoxic in human breast cancer MCF-7 and mammary epithelial MCF-12A cell lines. Exp Biol Med (Maywood) 229: 835-842, 2004.

22. Wang LG, Liu XM and Chiao JW: Repression of androgen receptor in prostate cancer cells by phenethyl isothiocyanate. Carcinogenesis 27: 2124-2132, 2006.

23. Preisler-Mashek MT, Solodin N, Stark BL, Tyriver MK and Alarid ET: Ligand-specific regulation of proteasome-mediated proteolysis of estrogen receptor-alpha. Am J Physiol Endocrinol Metab 282: E891-E898, 2002.

24. Nicholson RI, Gee JM, Manning DL, Wakeling AE, Montano MM and Katzenellenbogen BS: Responses to pure antiestrogens (ICI 164384, ICI 182780) in estrogen-sensitive and -resistant experimental and clinical breast cancer. Ann NY Acad Sci 761: 148-163, 1995.

25. Khan SA, Rogers MA, Obando JA and Tamsen A: Estrogen receptor expression of benign breast epithelium and its association with breast cancer. Cancer Res 54: 993-997, 1994.

26. Khan SA, Rogers MA, Khurana KK, Meguid MM and Numann PJ: Estrogen receptor expression in benign breast epithelium and breast cancer risk. J Natl Cancer Inst 90: 37-42, 1998.

27. Allegra JC, Lippman ME, Green L, Barlock A, Simon R, Thompson EB, Huff KK and Griffin W: Estrogen receptor values in patients with benign breast disease. Cancer 44: 228-231, 1979.

28. Van Agthoven T, Timmermans M, Dorssers LC and HenzenLogmans SC: Expression of estrogen, progersterone and epidermal growth factor receptors in primary and metastatic breast cancer. Int J Cancer 63: 790-793, 1995.

29. Fawell SE, White R, Hoare S, Sydenham M, Page M and Parker MG: Inhibition of estrogen receptor-DNA binding by the 'pure' antiestrogen ICI 164,384 appears to be mediated by impaired receptor dimerization. Proc Natl Acad Sci USA 87: 6883-6887, 1990

30. Dauvois S, White R and Parker MG: The antiestrogen ICI 182780 disrupts estrogen receptor nucleocytoplasmic shuttling. J Cell Sci 106: 1377-1388, 1993. 
31. De Graffenried LA, Hopp TA, Valente AJ, Clark RA and Fuqua SA: Regulation of the estrogen receptor alpha minimal promoter by Sp1, USF-1 and ER alpha. Breast Cancer Res Treat 85: 111-120, 2004.

32. Nilsson S, Mäkelä S, Treuter E, Tujague M, Thomsen J, Andersson G, Enmark E, Pettersson K, Warner M and Gustafsson JA: Mechanisms of estrogen action. Physiol Rev 81: 1535-1565, 2001.

33. Ji Y and Morris ME: Determination of phenethyl isothiocyanate in human plasma and urine by ammonia derivatization and liquid chromatography-tandem mass spectrometry. Anal Biochem 323: 39-47, 2003.
34. Liebes L, Conaway CC, Hochster H, Mendoza S, Hecht SS, Crowell $\mathrm{J}$ and Chung FL: High-performance liquid chromatography-based determination of total isothiocyanate levels in human plasma: application to studies with 2-phenethyl isothiocyanate. Anal Biochem 291: 279-289, 2001.

35. Ji Y, Kuo Y and Morris ME: Pharmacokinetics of dietary phenethyl isothiocyanate in rats. Pharm Res 22: 1658-1666, 2005.

36. Chen YR, Han J, Kori R, Kong AN and Tan TH: Phenylethyl isothiocyanate induces apoptotic signaling via suppressing phosphatase activity against c-Jun N-terminal kinase. J Biol Chem 277: 39334-39342, 2002. 